\title{
UTILIZAÇÃO DE OBJETOS DE APRENDIZAGEM NO ENSINO DA GEOMETRIA ESPACIAL.
}

\section{USE OF PHYSICAL OBJECTS OF LEARNING ON SPACE GEOMETRY TEACHING.}

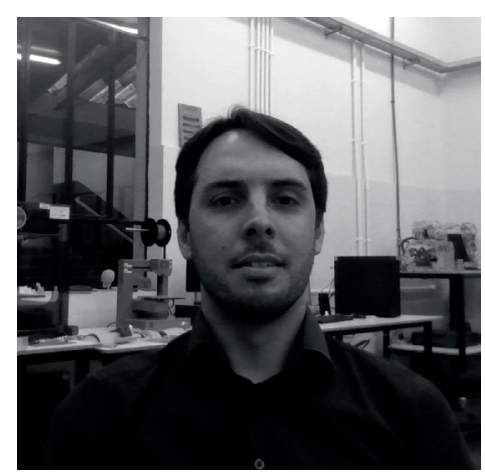

\section{Daniel Fritzen}

Professor dos Departamentos de Design e Engenharia Mecânica, Faculdade SATC. Criciúma/SC.

daniel.fritzen@satc.edu.br

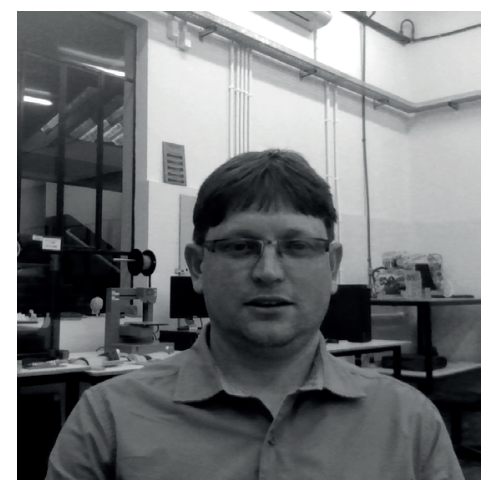

\section{Anderson Daleffe}

Professor do Departamento de Tecnologia em Manutenção Industrial, Faculdade SATC. Criciúma/SC. anderson.daleffe@satc.edu.br 


\section{RESUMO}

Costumeiramente, na disciplina de Desenho Técnico (DT), é comum ter alunos com dificuldades na compreensão da transição de perspectivas para vistas ortogonais (bidimensionais) e vice-versa. Este artigo apresenta a utilização dos Objetos Físicos de Aprendizagem (OFAs) nas aulas da disciplina de Desenho Técnico e suas possibilidades de aprimoramento do processo de ensino-aprendizagem, discutindo os resultados quantitativos (notas) de alunos de turmas diferentes, onde neste caso, se observou significativo aumento no número de alunos com aprovação direta na disciplina de Desenho Técnico, quando expostos a utilização dos Objetos Físicos de Aprendizagem, produzidos por impressão 3D no laboratório PRONTO 3D.

\section{PALAVRAS-CHAVE}

Objetos Físicos de aprendizagem; Desenho Técnico; Ensino-aprendizagem; PRONTO 3D.

\section{ABSTRACT}

Customarily, in the Technical Drawing discipline, it is common to have students with difficulties in understanding the transition from perspectives to orthogonal views (two-dimensional), and the opposite. This paper shows the use of rapid prototyping and digital manufacture resources at Technical Drawing classrooms and its possibilities of improvement of the teaching-learning process, discussing the quantitative results of students from different classrooms, where in this case, it was observed a significant increase in the number of students with direct approval in the Technical Drawing discipline.

\section{KEYWORDS}

Rapid Prototyping; Digital Manufacture; Technical Drawing;Teaching-learning; PRONTO 3D.

\section{INTRODUÇÃO}

No final do século XX começava a se desenhar a terceira revolução industrial. Uma revolução pautada principalmente na sociedade do conhecimento e na hiperindividualização da produção e que terá um impacto tão significativo no século XXI como a primeira revolução industrial no século XIX e a segunda no século XX (GOMEZ, 2015, p. 65). As etapas de elaboração de produtos e prestação de serviços, desde a sua concepção até a sua comercialização serão pro- 
fundamente modificadas. Dessa forma, o projeto pedagógico dos cursos de Design (notadamente nas áreas de produto, moda e games), para se adequar a esta nova cultura de consumo e produção, devem evoluir, atualizar-se e acompanhar esta tendência global.

A pesquisa acadêmica e a execução de experimentos baseados neste novo contexto se tornam recursos importantes para o desenvolvimento de competências e habilidades docentes e discentes. A existência de ambientes colaborativos e devidamente equipados, bem como o envolvimento e participação de professores e alunos nos projetos de pesquisa, podem contribuir para esta nova perspectiva de ensino.

Tradicionalmente, na disciplina de Desenho Técnico as aulas expositivas em lousa e/ou pranchetas ainda é o método mais adotado. Porém este método secular não atende em plenitude todos os alunos, uma vez que nem todos possuem um médio ou alto nível de aptidão espacial, o que nestes casos, a utilização de recursos de prototipagem rápida e fabricação digital beneficia os alunos com dificuldades na aprendizagem.

Deste modo, o presente artigo aborda a importância de um espaço colaborativo devidamente equipado, voltado a materialização (Prototipagem, Maquetes, Produtos Finais, entre outros) de recursos que auxiliam no processo de ensino-aprendizagem. Especificamente, se defende a relevância do emprego de recursos de prototipagem rápida e fabricação digital nas aulas de Desenho Técnico, produzidos no laboratório PRONTO 3D, de Criciúma/SC.

\section{A REDE PRONTO 3D}

O PRONTO 3D - Laboratório de Prototipagem e Novas Tecnologias Orientadas ao 3D - é uma rede de cooperação científica e conta atualmente com quatro unidades (Florianópolis, Criciúma, Lages e Chapecó). Suas atividades destinam-se ao ensino, pesquisa e extensão na área da materialização de produtos. Estes produtos constituem-se de objetos de aprendizagem, protótipos, maquetes e demais projetos docentes e discentes, e são fabricados via impressoras 3D, máquinas de corte laser e fresadoras router CNC. A unidade PRONTO de Criciúma é coordenada por dois professores-doutores. Além destes, dois professores e dois graduandos-bolsistas cuidam da operação, manutenção e agendamento de atividades no laboratório.

A Rede PRONTO 3D atende cursos de Design, Arquitetura, Engenharias, bem como todas as áreas que envolvam criação, desenvolvimento e produção de modelos, protótipos, maquetes e produtos em escala real, auxiliando as dife- 
rentes etapas do processo de projeto. Recentemente, a REDE PRONTO 3D se afiliou à REDE FabLab Brasil, que faz parte da rede internacional FabLab e é composta por mais de 200 laboratórios ao redor do mundo (PRONTO, 2015).

\subsection{DESENVOLVENDO E UTILIZANDO OS RECURSOS DE PROTO- TIPAGEM RÁPIDA E FABRICAÇÃO DIGITAL}

O termo "objetos de aprendizagem" está fortemente associado a "recursos computacionais para dar suporte ao ensino", de acordo com a IEEE (IEEE, 2015). De fato, pesquisas utilizando este termo estarão quase sempre associadas ao $\mathrm{EaD}$ e aos objetos virtuais de aprendizagem, tais como apresentadas por Bulegon (2011), Silva (2011), Nunes et al (2014) e Frade et al (2014).

Com a imersão digital dos tempos atuais, é possível virtualizar praticamente qualquer experiência ou conteúdo acadêmico. Porém, para o ensino da Representação Gráfica Espacial, a utilização de suportes físicos demostra ser eficiente, pois há, além da interação visual, a tátil. Percepções de forma, volume e massa são assimiladas mais rapidamente. Por isto, a utilização de "objetos físicos de aprendizagem" (OFA) é plenamente justificada.

Neste contexto, Dezen-Kempter et al. (2012) relatam em sua pesquisa a utilização de modelos tridimensionais esculpidos em madeira, associados a uma maquete em madeira de uma simulador de diedro (Figura 1), possibilitando aos alunos o desenvolvimento da capacidade de representação gráfica no primeiro e terceiro diedros de Gaspar Monge.
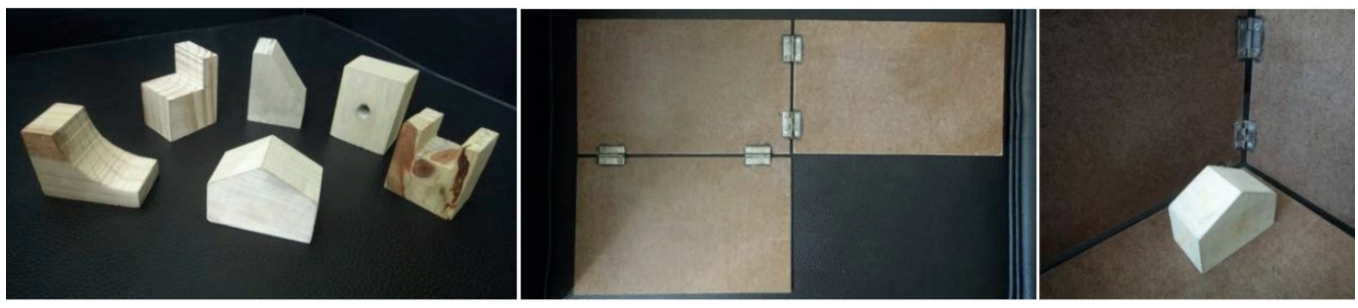

Figura 1: Objetos Físicos de Aprendizagem: Modelos Físicos e Simulador físico de Diedro.

Dezen-Kempter et al. (2012)

Silva (2011) aborda em seu trabalho a importância dos conceitos de Geometria Descritiva (GD) e Desenho Geométrico (DG) bem definidos para o aluno, pois são bases imprescindíveis para a melhor aprendizagem da representação gráfica em de Desenho Técnico (DT), que neste caso, sentencia que a criação de modelos físicos complementam a aprendizagem, inclusive do modelo virtual (aulas em software CAD 3D), apresentando a necessidade de conceitos prelimi- 
nares (GD + DG) que o papel aceita, mas que nos softwares CAD não se concretiza, ou apresenta-se tamanha complexidade para resolver.

\section{METODOLOGIA}

Para este artigo, são apresentados quatro aplicações de OFAs desennvolvidos dentro da unidade PRONTO 3D de Criciúma e utilizados nas disciplinas de Desenho Técnico dos cursos de Design, Engenharia Mecânica e Tecnologia em Manutenção Industrial da Faculdade SATC, de Criciúma - SC. Cada OFA será discutido, apresentando os resultados quantitativos (notas) coletados dos discentes e qualitativos (comentários) observados pelos docentes. A discussão da aplicação de cada OFA dar-se-á em função da comparação entre classes que foram expostas a esta aplicação, e a classes que não tiveram contato com OFAs nas aulas.

\subsection{CASE 1: CUBO E O DESENHO TÉCNICO}

O primeiro exemplo de objeto de aprendizagem, fabricado no PRONTO 3D é o cubo chanfrado (Figura 1b). De acordo com o plano de ensino da disciplina de Desenho Técnico, aplicada aos cursos de Engenharia Mecânica e Design da Faculdade SATC, este cubo é utilizado na 7a. aula da disciplina. Nas aulas anteriores são apresentados os conceitos fundamentais da Geometria Descritiva (convenções, fundamentos e projeção de retas, planos e poliedros). Assim, na 7a. semana inicia-se o Desenho Técnico propriamente dito, com projeções de peças diversas, iniciando com as primitivas didáticas (pirâmides, cones, cilindros, prismas e prismas combinados) até peças de chão de fábrica e produtos de uso.

A apresentação de um cubo normalmente gera uma reação de indiferença ou de pouca importância por parte dos alunos, devido à sua aparente simplicidade. Porém, é possível explorar diversos aspectos, incluindo a identificação e contagem dos elementos morfológicos, sua situação em relação aos planos de projeção, a identificação dos tipos de reta que as arestas representam, a identificação da aresta invisível nos planos projetivos (devido ao detalhe chanfrado), à sobreposição e ordenamento dos pontos (vértices), à planificação e aos processos de obtenção de verdadeira grandeza da superfície chanfrada que, por estar em um plano qualquer, exige um processo mais elaborado para obtê-la. 


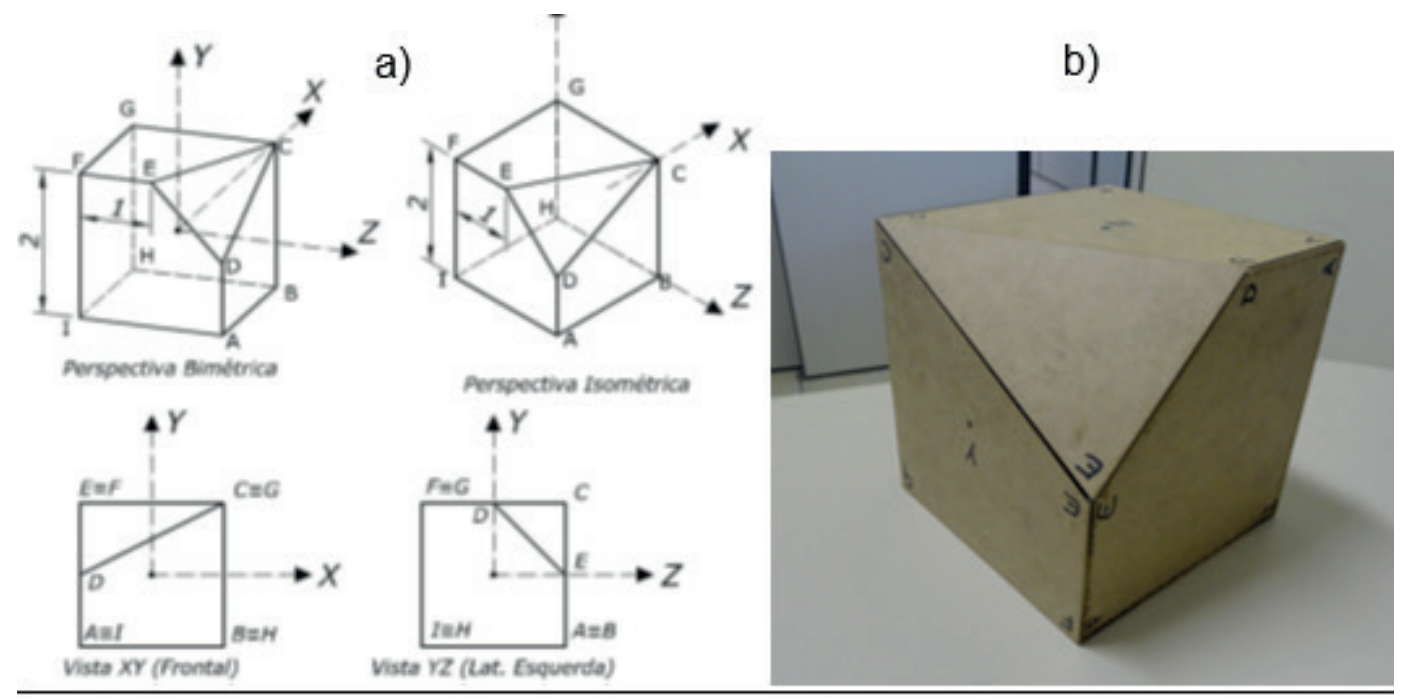

Figura 2. Conteúdo de vistas ortogonais exemplificado pelas projeções de um cubo chanfrado. a) forma tradicional, apresentada em slide ou desenhada no quadro; b) objeto físico de aprendizagem.

\subsection{CASE 2: A MESA DAS COORDENADAS ESPACIAIS}

O segundo exemplo de objeto de aprendizagem idealizado e fabricado dentro da unidade PRONTO 3D de Criciúma é a Base de Coordenadas Espaciais (Figura 3). Este objeto auxilia na explicação sobre os três diferentes sistemas de coordenadas (cartesianas, cilíndricas e esféricas) que podem ser utilizados nos softwares CAD para entrada de dados, para um construção 3D em forma de arame (somente linhas). Como envolve três eixos, o desenho no quadro branco é sempre de compreensão mais difícil, devido à construção em perspectiva estática e à sobreposição de informações. A utilização de objetos de aprendizagem virtuais auxilia um pouco, embora o aluno não consiga se aproximar e criar uma maior interação, o que é possível com o uso da Base de Coordenadas.

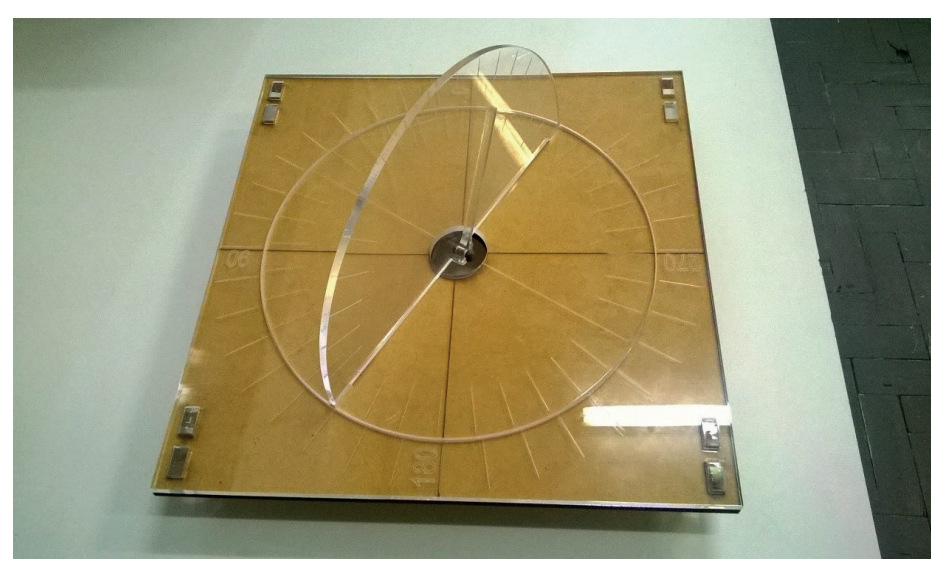


Figura 3. Base de Coordenadas utilizada para exemplificar os diferentes sistemas de coordenadas utilizadas em sistemas CAD.

A utilização de Base de Coordenadas Espaciais como OFA nas aulas de Coordenadas Espaciais proporcionou aso discentes, além da visão espacial caracterizada na prática, a intereção com o objeto, seja no momentos de explicação tradicional (Docente /Discente), entre os próprios discentes (Discente /Discente), ou ainda, em alguns casos, o próprio Discente apenas utilizando o OFA.

\subsection{CASE 3: PROJEÇÃO ORTOGONAL COM OFAS}

O terceiro exemplo de OFAs são peças e produtos de uso, fabricados por impressão 3D e corte a laser (Figura 4), que são entregues aos alunos para realização de tarefas de aprendizagem associadas à Representação Gráfica Espacial, tais como a análise morfológica, medições, construção das vistas ortogonais e estudo das sequências de montagem/desmontagem.

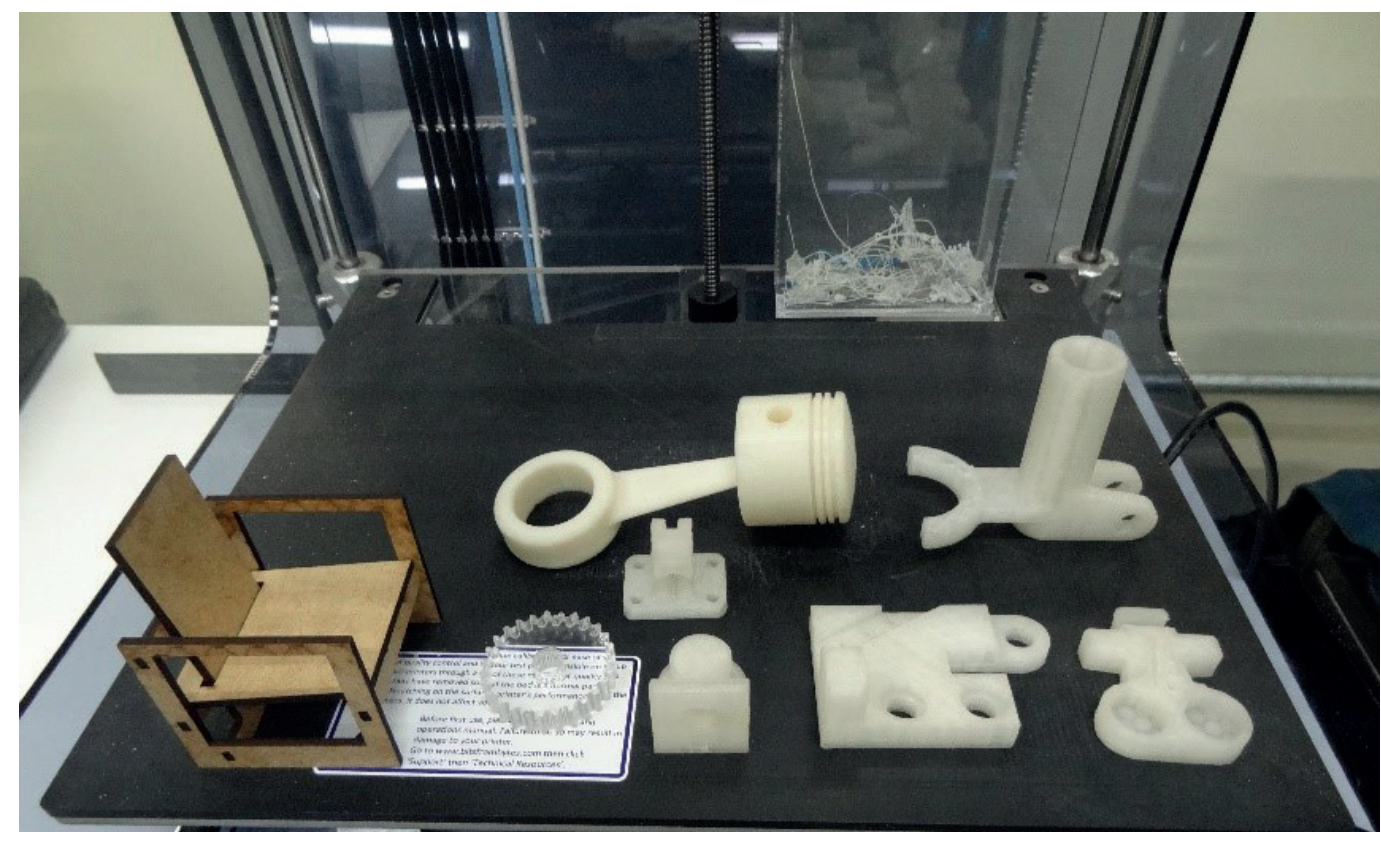

Figura 4. Peças e produtos materializados para estudo de sua representação em vistas ortogonais.

As atividades propostas neste Case, além da elaboração das projeções ortogonais dos modelos 3D entregues, exigiram dos discentes a utilização de instrumentos de medição, sobretudo de paquímetros, e assim, também desenvolvendo esta habilidade. 


\subsection{CASE 4: PROJETO E EXECUÇÃO DE SUPORTE}

O Case 4 aborda praticamente as mesmas atividades propostas neste Case anterior, ou seja, modelos tridimensionais impressos e medição por paquímetro, contudo, o objetivo da atividade era o projeto e execução de suportes de montagem que atendessem as necessidades impostas. Os discentes foram organizados em duplas, onde cada equipe recebeu um desenho projetivo com duas peças (sem dimensões) diferentes e não montadas, mas alinhadas (Figura 5a), e os modelos tridimensionais impressos (Figura 5b).

(a)
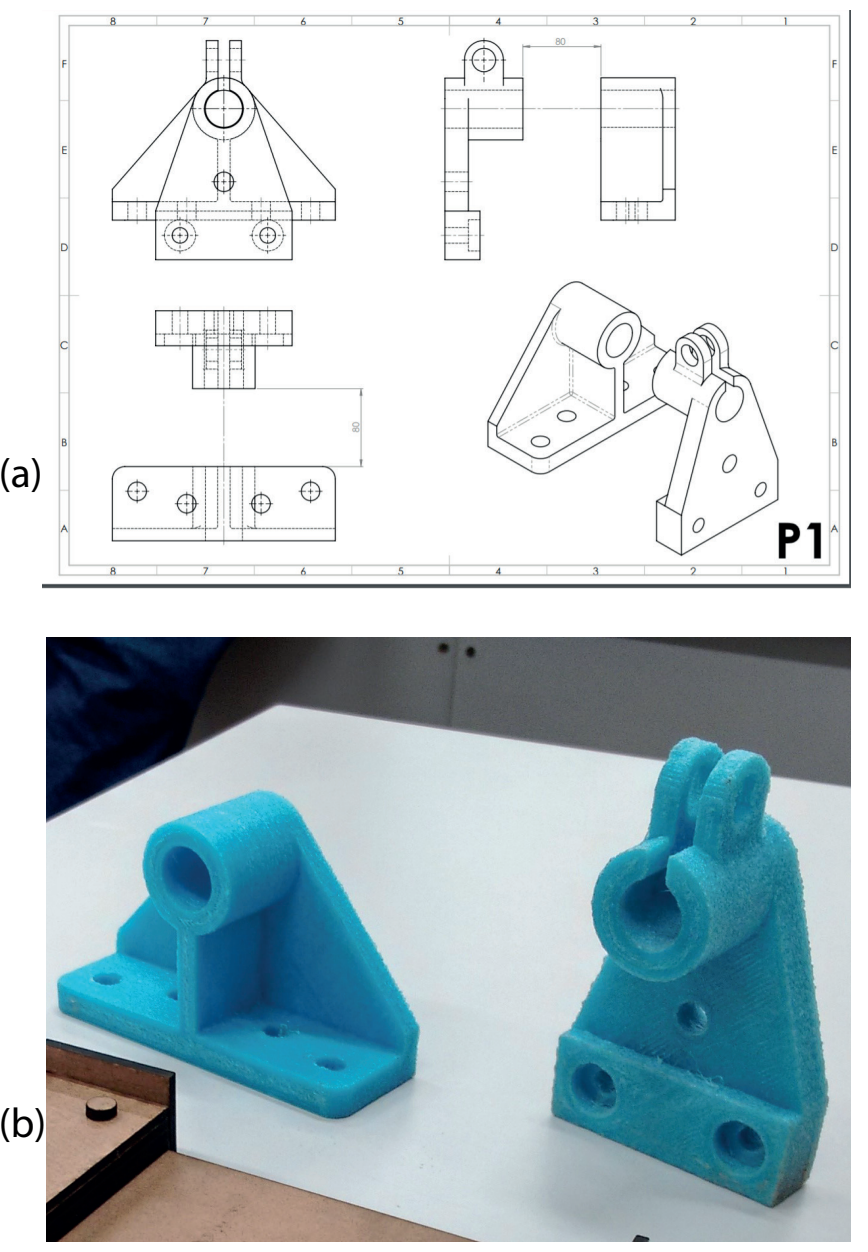

Figura 5. Peças alinhadas de sua representação em vistas ortogonais.

O fluxograma de trabalho dos acadêmicos se iniciou com a elaboração das vistas ortogonais modelos tridimensionais impressos, de modo que para esta atividade, os discentes tiveram que utilizar paquímetro. A segunda etapa se caracterizou em esboçar (desenho a mão livre em grafite) o suporte de acordo 
com projeções ortogonais (Figura 5a) e as dimensões medidas dos modelos 3D. A quarta etapa transcorreu como o projeto em CAD e a quinta etapa, como a fabricação de cada peça projetada, utilizando a máquina de corte a laser do laboratório PRONTO 3D. A validação do exercício se deu com a montagem das peças no suporte fabricado (Figura 6) e a apresentação dos desenhos de esboço e impressos, de acordo com as normas ABNT de Desenho Técnico.

(a)

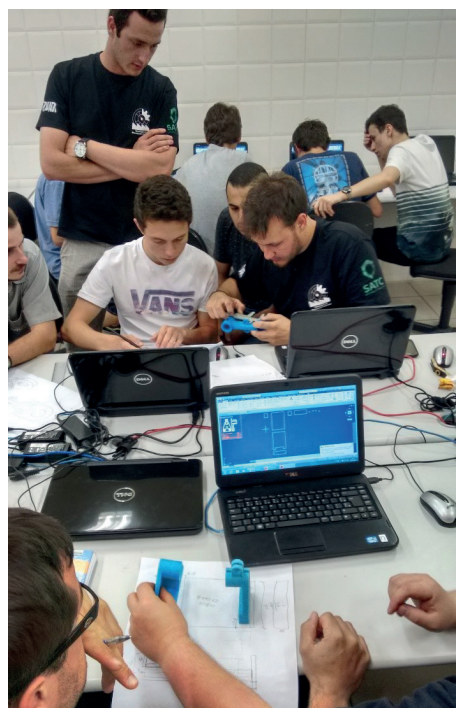

(b)

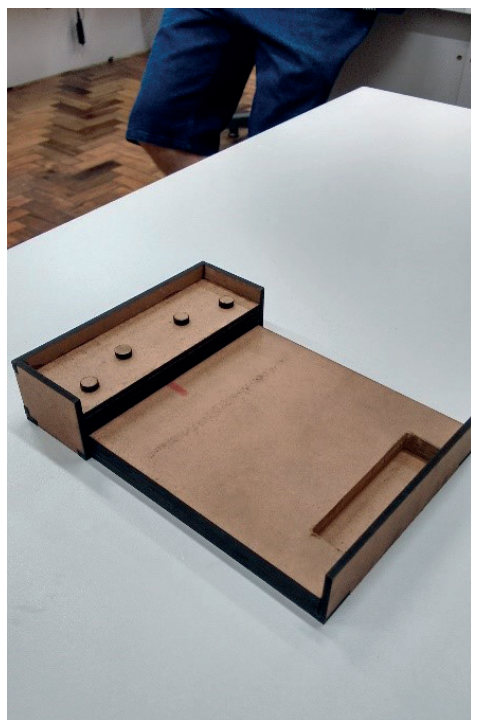

(c)

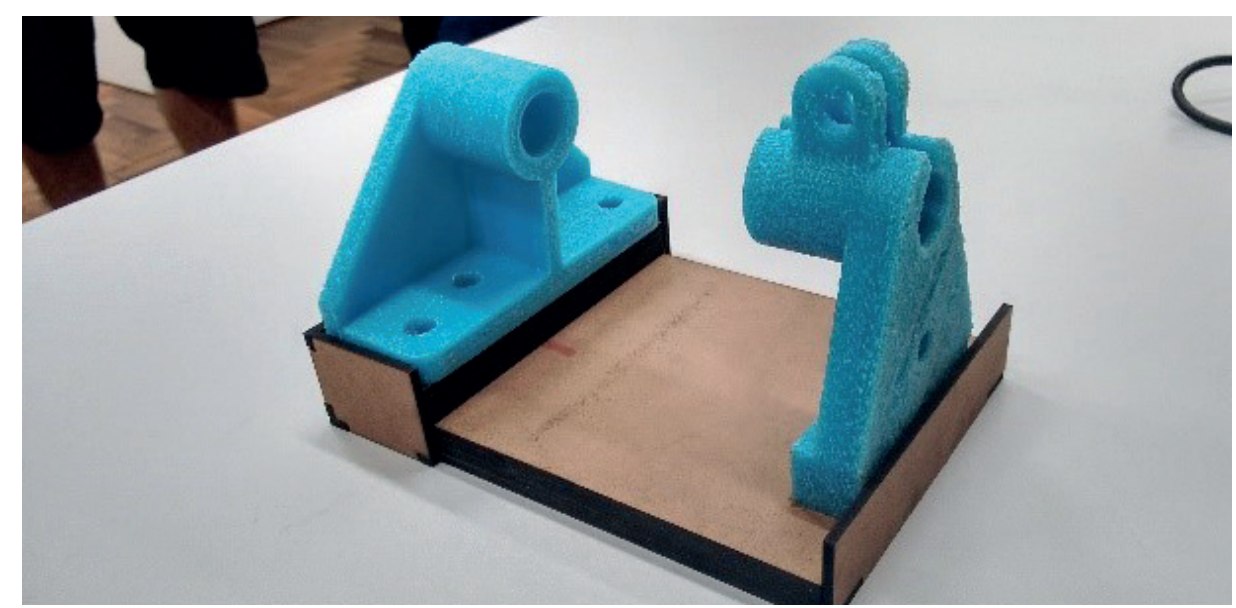

Figura 6. Fabricação de Suportes de Montagem: a) Medição, esboço 2D e projeto $C A D$; b) Suporte fabricado; c) Conjunto de Peças montadas no Suporte.

\section{ANÁLISE E DISCUSSÃO DOS RESULTADOS}

A análise e discussão dos resultados qualitativos e quantitativos dos trabalhos 
apresentados serão feitas separadamente, conforme as estruturas dos Cases mencionadas anteriormente.

\subsection{CASE 1: CUBO E O DESENHO TÉCNICO}

Sendo o conteúdo apresentado da forma tradicional (Figura 2a), uma quantidade maior de alunos apresenta dificuldades, refletidas nas notas da $1^{\text {a }}$ e $2^{\text {a }}$ prova, feita na $13^{a}$ semana de aula. $O$ desempenho quantitativo dos discentes pode ser observado na Figura 7.

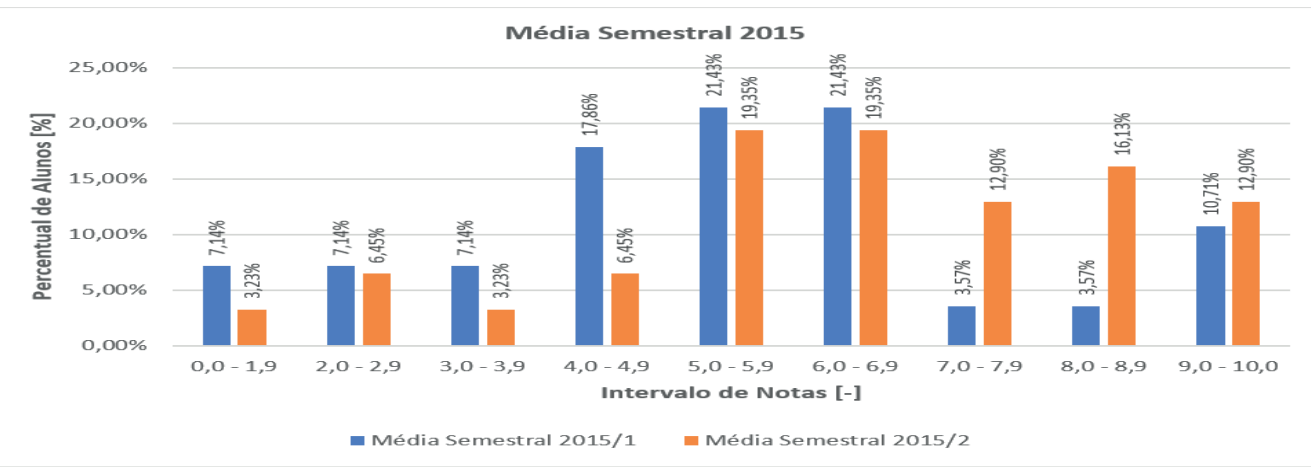

Figura 7. Aproveitamento da turma 2015/01, sem uso de OFA.

Analisando os dados do gráfico da Figura 7, se observa que as notas acima de 6,00 (ponto de corte para aprovação direta) estão mais concentradas com os discentes que utilizaram OFA durante as aulas de Desenho Técnico, e por conseguintes, há menos discentes com notas abaixo de 6,00, como apresenta a Figura 8.

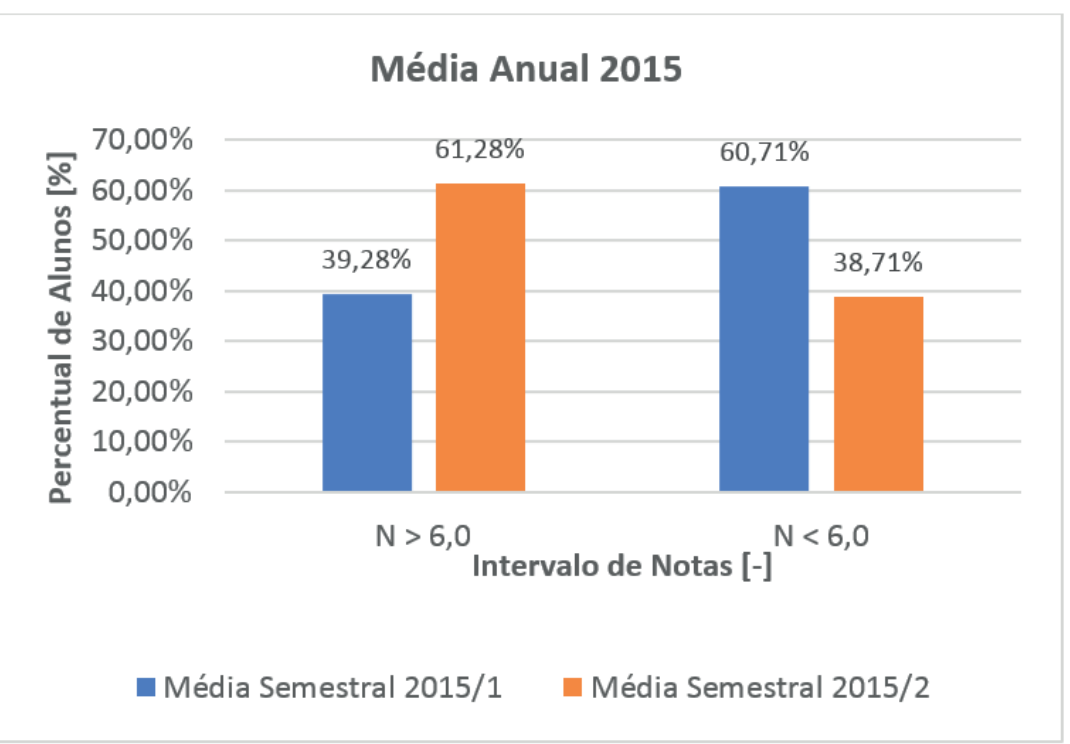


Figura 8. Comparativo do aproveitamento por semestre, considerando o ponto de corte para aprovação direta.

Em uma análise direta, um objeto físico permite o toque, a visualização em diversos ângulos, a análise minuciosa de um detalhe geométrico, a aproximação e visualização mais confortável, a noção exata de proporcionalidade dimensional, enfim, uma série de situações que facilitam o entendimento, contribuindo para a assimilação mais eficiente e perene daquele conteúdo.

\subsection{CASE 2: A MESA DAS COORDENADAS ESPACIAIS}

No primeiro semetre do ano de 2016, conteúdo de Coordenadas Espaciais foi ministrado sem a utilização de OFAs, ao contrário do segundo semestre do mesmo ano. Quantitativamente, os alunos expostos a aplicação de OFAs no processo de ensino-aprendizagem obtiveram uma maior concentração de notas acima de 6,00, como no Case anterior, mas de não tão significativamente. Porém, se observa uma diferença significativa no número de alunos com notas abaixo 4,00 (Figura 9).

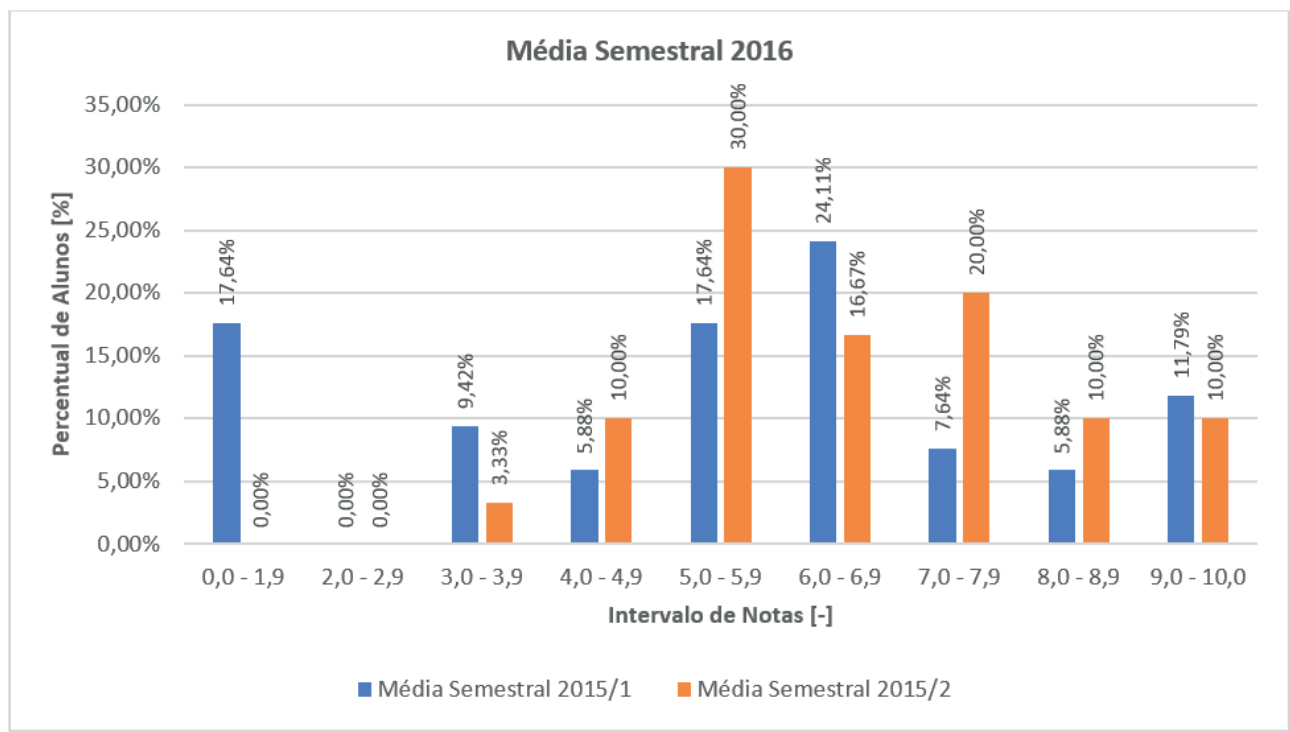

Figura 9. Comparativo do aproveitamento por semestre, considerando o ponto de corte para aprovação direta.

A Figura 10 apresenta o percentual de discente em função do valor 6,00, e tam- 


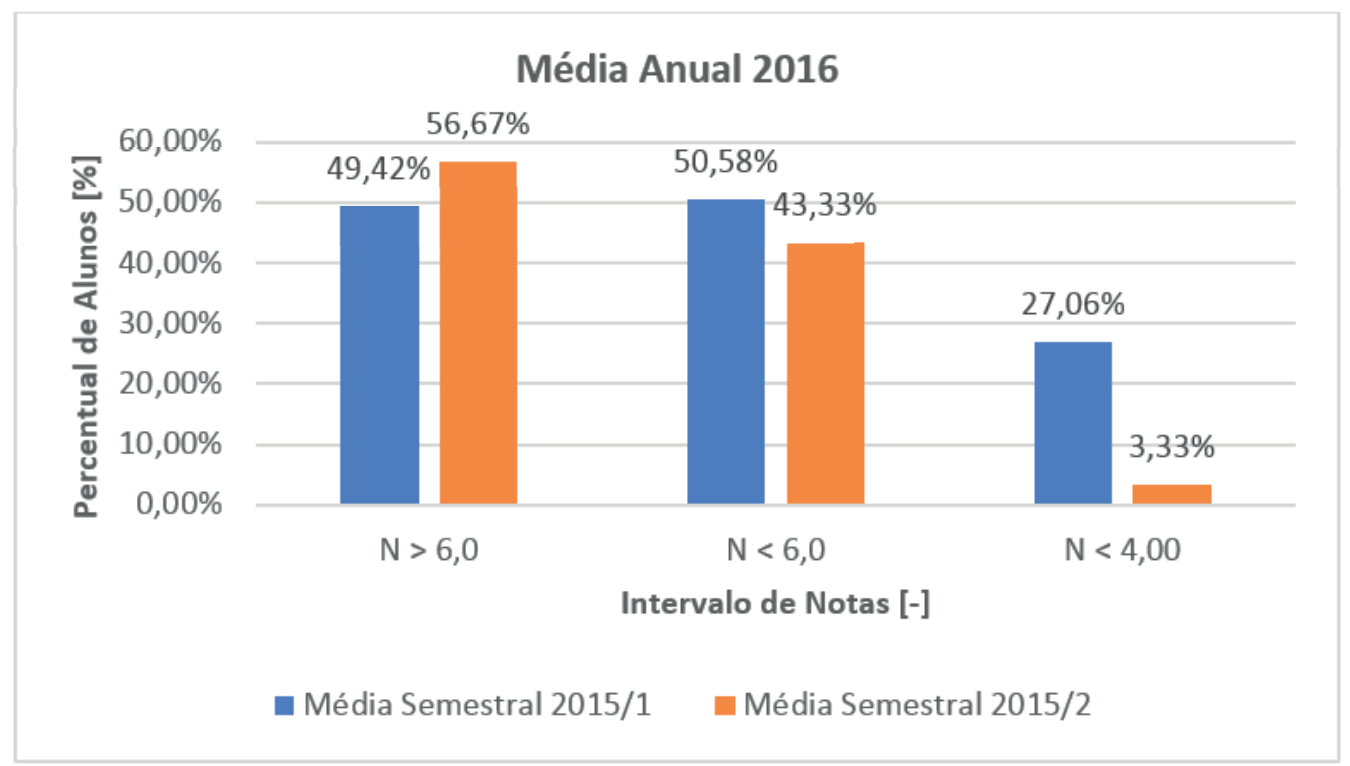

Figura 10. Comparativo do aproveitamento por semestre.

\subsection{CASE 3: PROJEÇÃO ORTOGONAL COM OBJETO DE APREN- DIZAGEM}

Dentre os quatro Cases abordados, apenas este Case tratou os resultados de forma qualitativa, onde, o docente observou o comportamento dos discentes na resolução dos problemas propostos. A avalição por parte do professor, muito embora subjetiva, se apoiou no poder de resolução dos desenhos sem a inteferência ou ajuda do docente. Ficou evidente a cooperação entre os discentes, tanto no aspecto de medição das peças, quanto - e principalmente - na correta elaboração dos desenho técnicos, respeitando e aplicando corretamente as normas de Desenho Técnico mecânico. Ficou evidente que a utilização de objeto de aprendizagem neste processo contribuiu nas discussões entre discentes, que defendiam suas "teses" de resolução dos desenhos, manipulando e mostrando aos demais discentes, o que contribui de forma grandiosa na retenção destas competências para o acadêmico.

\subsection{CASE 4: PROJETO E EXECUÇÃO DE SUPORTE}

Para este Case, se faz o registro que para os contetúdos ministrados para a realização da Avaliação 1 (Geometria Descritiva) e Avaliação 2 (Desenho Técnico Mecânico) não foram utilizados objeto de aprendizagem nas aulas, e estas, tiveram um carater estritamente expositivo. $O$ contato dos acadêmicos com objeto de aprendizagem se deu apenas na ultima avaliação. Muito embora o produto final tenha sido o suporte, fabricado na máquina de corte a laser a partir dos 
desenhos CAD, 40\% do peso da avalição estava sobre os desenhos esboçados em papel, considerando a aplicação das normas da ABNT de Desenho Técnico. Os resultados alcançados com esta avaliação estão expostos na Figura 11.

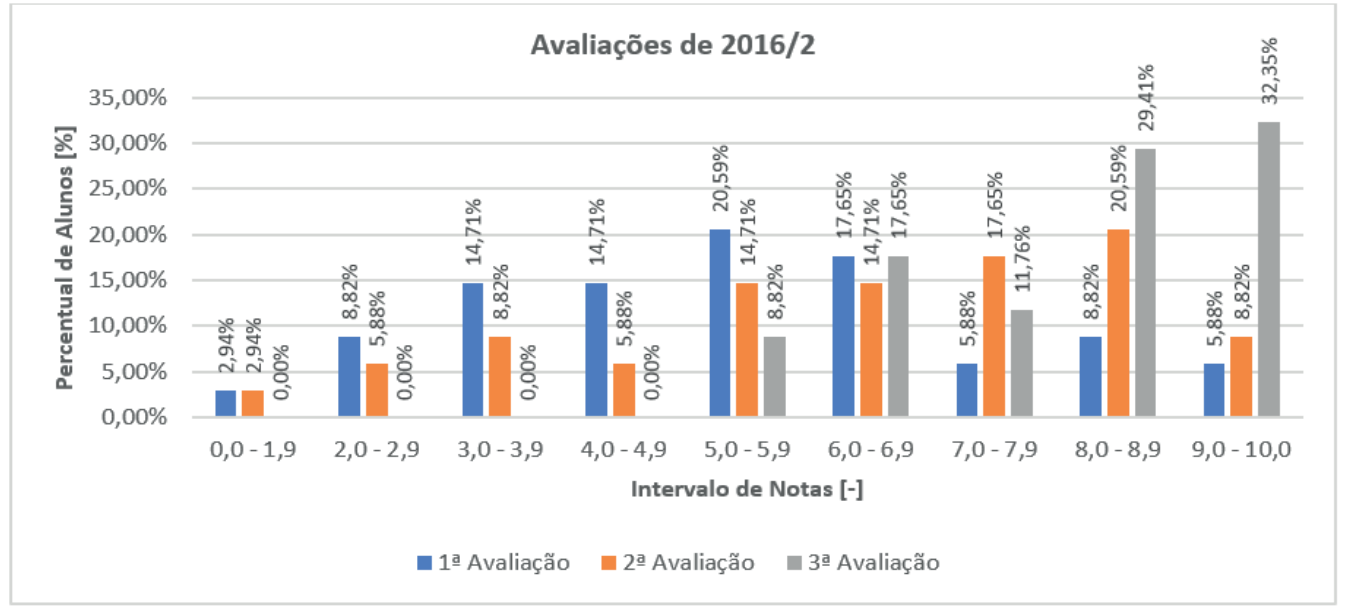

Figura 11. Comparativo do aproveitamento por avaliação.

A Figura 12 apresenta os resultados agrupados das três avaliações realizadas durante o segundo semestre de 2016, na aula de Desenho Técnico - CAD. Desta figura se observa que na primeira avaliação (Geometria Descritiva) a maior parte dos discentes $(61,77 \%)$ não obteve nota acima de 6,00 , e não foram expostos a utilização de objeto de aprendizagem . A segunda avaliação (Desenho Técnico) apresenta números melhores, pois apenas 38,23\% dos discentes não obtiveram nota acima de 6,00. Todavia, a avalição 3 (Desenho Técnico + CAD), exposta a aplicação de objeto de aprendizagem concentrou apenas $8,82 \%$ dos acadêmicos com nota abaixo de 6,00 e nenhum abaixo de 4,00.

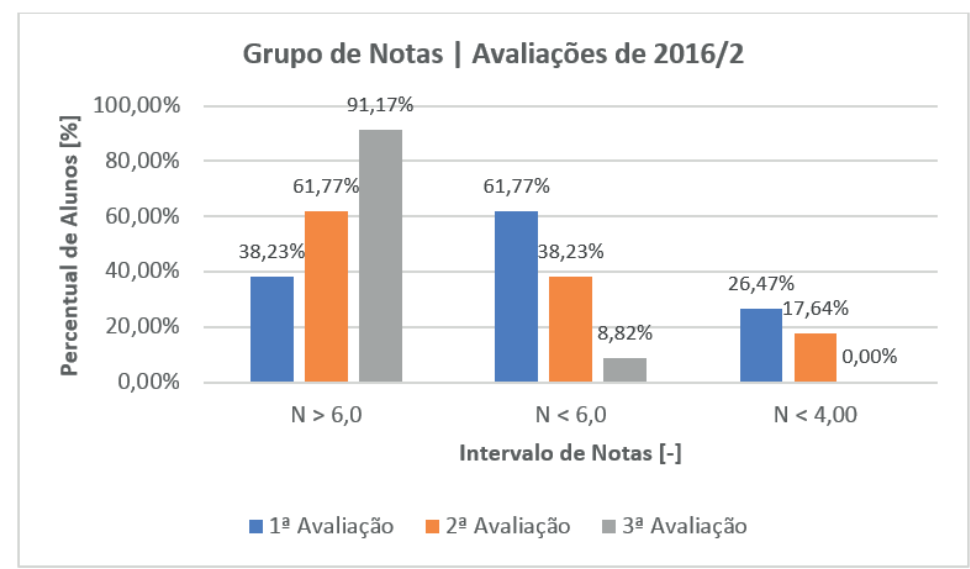


Figura 12. Comparativo do grupo de notas.

\section{CONSIDERAÇÕES FINAIS}

Analisando os percentuais das notas dos alunos, obtidas em semestres consecutivos, é possível demostrar a eficiência da utilização dos objeto de aprendizagem nas aulas de Desenho Técnico. A Figura 8 apresenta inversão do percentual de acadêmicos com o aproveitamento superior a nota de aprovação $(6,00)$, alterando de $39,28 \%$ do primeiro semetre, para $61,28 \%$ para o segundo semestre. Do mesmo modo, os dados apresentados na Figura 10 indicam uma melhora do percentual de acadêmicos com nota superior a 6,00, neste caso, de 49,42\% do primeiro semetre, para $56,67 \%$ para o segundo semestre. Adicionalmente, para esta Case, percebe-se a redução quase total dos acadêmicos com nota inferior a 4,00.

Para ambos casos, que abordam dois semestres distintos, registra-se que não houveram alterações na ementa, nos objetivos da disciplina e nem no nível de dificuldade das provas, vê-se nitidamente um melhor aproveitamento dos alunos do segundo semestre. Todavia, deve-se considerar, que se tratam de turmas diferentes e diferenças no percentual de aprendizagem podem estar intrísecas à capacidade intelectual dos indivíduos. Sob este aspecto, também é importante considerar que o perfil sócio-econômico-cultural é o mesmo: alunos da classe $C$, oriundos de escola pública e que nunca tiveram contato com a disciplina. Complementando os dados quantitativos, a Figura 12 também apresenta números otimistas de acadêmicos com nota superior a 6,00 (91,17\%), e principalmente, com notas abaixo de 4,00, neste caso, nenhum.

De qualquer forma, os resultados apresentados são suficientes para justificar a implementação destes objetos em sala de aula, pois não somente as notas dos discentes melhoram, mas também houve incremento da avaliação docente (as notas do professor, avaliado pelos alunos, foram 8,7 e 9,2 no $1^{\circ}$. e $2^{\circ}$. semestre, respectivamente). Demonstra-se, portanto, a contribuição dos objetos de aprendizagem para o aprimoramento do processo ensino-aprendizagem para as disciplinas relacionadas à área de Representação Gráfica Espacial.

\section{AGRADECIMENTOS}

Os autores agradecem a Faculdade SATC pelo constante apoio técnico e incentivo na implementação de novas práticas de ensino-aprendizagem, bem como a Rede PRONTO 3D por toda a infraestrutura disponibilizada. 


\section{REFERÊNCIAS}

.Rede PRONTO 3D. Acessado em 23 abril 2015. Disponível em: http:// www.redepronto3d.com/

.IEEE - International Eletrical and Eletronic Engineers. Acessado em 23 março 2015. Disponível em: www.ieee.org.

BULEGON, Ana Marli. Contribuições dos objetos de aprendizagem, no ensino de física, para o desenvolvimento do pensamento crítico e da aprendizagem significativa. Tese de Doutorado. Porto Alegre.: UFRGS. Universidade Federal do Rio Grande do Sul. Centro de Estudos Interdisciplinares em Novas Tecnologias da Educação. Programa de Pós-Graduação em Informática na Educação., 2011.

DEZEN-KEMPTER, E; CORGHI , F. N.; FERRAZ, A. L. A.; COSTA, D. C. DA. Desenho Técnico Aplicado aos Cursos Superiores de Tecnologia Ambiental e Construção Civil. XL Congresso Brasileiro de Educação em Engenharia (COBENGE 2012), Belém - PA, 2012.

FRADE, R. V. C.; NETO F. M. M.; LIMA R. W.; SILVA, L. C. N.; SOUZA R. C. Um Ambiente Virtual 3D Multiagente com Recomendação Personalizada de Objetos de Aprendizagem. III Congresso Brasileiro de Informática na Educação (CBIE 2014). XXV Simpósio Brasileiro de Informática na Educação (SBIE 2014), Dourados - MS, 2014.

GOMEZ, L. S. R. Ser maker está na moda: como as marcas devem agir na fabricação digital. Transitos Vestíveis, Florianópolis, Editora da UDESC, 2015, p. 65.

NUNES, F. B.; MOURA, T. B.; MARIA, S. S. A; BEHAR, P. A. Um estudo de caso sobre a importância do uso de objetos de aprendizagem no ensino fundamental como apoio pedagógico. $3^{\circ}$ Congresso Brasileiro de Informática na Educação (CBIE 2014). 20a Workshop de Informática na Escola (WIE 2014), Dourados - MS, 2014.

SILVA, Júlia Marques Carvalho da. Análise técnica e pedagógica de metada- 
dos para objetos de aprendizagem., Tese de Doutorado. Porto Alegre: UFRGS. Universidade Federal do Rio Grande do Sul. Programa de Pós-graduação em Informática na Educação, 2011.

SILVA, E. C. Da. Ensino do Desenho nos Cursos de Engenharia e Design. XXIX Congresso Brasileiro de Educação em Engenharia (COBENGE 2011), Blumenau - SC, 2011

\section{Daniel Fritzen}

Professor da Faculdade SATC. Possui graduação em Tecnologia em Automação Industrial (UNESC/SC - 2005), Especialista em Psicopedagogia Institucional pela (UCB/RJ -2008). Mestrado (2012) e Doutorado (2016) em Engenharia de Minas, Metalúrgica e de Materiais pelo PPGE3M/UFRGS. Tem experiência na área de educação, (Ensino técnico e superior), ministrando disciplinas ligadas a Desenho Técnico, CAD/CAM/CNC e Computação Gráfica. Possui experiência na indústria 66 com projetos mecânicos, PCP e custos da produção. Possui linhas de pesquisas ligadas a área conformação de chapas, em especial a Estampagem Incremental de Chapas, ligadas a área biomédica, com o projeto de próteses customizáveis. Também atua em pesquisas relacionadas a prática docente em sala de aula, com o desenvolvimento de novos processos/ferramentas que auxiliem na educação superior, usando as Metodologias Ativas de Aprendizagem.

\section{Anderson Daleffe}

Doutor pela Universidade Federal do Rio Grande do Sul - UFRGS no programa de Engenharia de Minas, Metalurgia e de Materiais, área de concentração Processos de Fabricação. Graduado como Tecnólogo em Eletromecânica pela Universidade do Extremo Sul Catarinense. Pós-graduado em Psicopedagogia Institucional. Mestre em Engenharia, área de concentração Processos de Fabricação - UFRGS. Tem experiência na área de educação no ensino superior, atuando principalmente nos seguintes temas: fabricação, usinagem convencional, usinagem CNC, robótica e manutenção industrial. Possui também experiência 
industrial em processos de fabricação, CAM, usinagem convencional e CNC. Coordenador do Laboratório de Prototipagem Rápida - Pronto 3D, Criciúma/Faculdade SATC. Professor da disciplina de Estampagem de Chapas do Mestrado em Engenharia Metalúrgica da FACULDADE SATC. Professor do curso de graduação em Tecnologia em Manutenção Industrial, Engenharia Mecânica e pesquisador da FACULDADE SATC - Criciúma - S.C.

DATA DE SUBMISSÃO: 26/07/2017.

DATA DE ACEITE: 29/08/2017. 